\title{
"humanidades
}

Revista Humanidades

ISSN: 2215-3934

humanidades@ucr.ac.cr

Universidad de Costa Rica

Costa Rica

\section{Fundamentos neurocognitivos como sustrato para un diseño intuitivo}

Solano Meneses, Dra. Eska Elena

Fundamentos neurocognitivos como sustrato para un diseño intuitivo

Revista Humanidades, vol. 11, núm. 1, 2021

Universidad de Costa Rica, Costa Rica

Disponible en: http://www.redalyc.org/articulo. oa?id=498064330007

DOI: https://doi.org/10.15517/h.v11i1.44156 
Desde las ciencias sociales, filosofía y educación

\section{Fundamentos neurocognitivos como sustrato para un diseño intuitivo}

Neurocognitive Principles as the Basis for an Intuitive Design

Dra. Eska Elena Solano Meneses

Universidad Autónoma del Estado de México. Centro de

Investigación en Arquitectura y Diseño, México

DOI: https://doi.org/10.15517/h.v11i1.44156

Redalyc: http://www.redalyc.org/articulo.oa?

eskasolano@gmail.com

(D) http://orcid.org/0000-0002-5974-1511

$\mathrm{id}=498064330007$

Recepción: 27 Abril 2020

Aprobación: 18 Junio 2020

\section{Resumen:}

Este trabajo busca analizar las implicaciones de las ciencias neurocognitivas en el diseño. Estudios recientes permiten reconceptualizar los planteamientos del diseño desde la semiótica. Los científicos John O 'Keefe, Edvard Moser y May-Britt Moser han descubierto la existencia de células en el cerebro cuyo sistema permite que las personas se puedan ubicar creando un mapa mental del espacio físico. De lo anterior se introduce el concepto de Wayfinding, el cual hace referencia a la manera en que mentalmente se planea el desplazamiento por un lugar o el uso de un objeto, no como un símil de un mapa visual-mental, sino como un proceso que involucra componentes simbólicos y experiencias pasadas determinantes. El Wayfinding demanda diferentes tipos de memoria: los recuerdos episódicos y los habituales o "rígidos", la respuesta de ellos desde el diseño se denomina el Wayshowing, es decir, la aplicación de estos conocimientos al diseño. En este sentido, se toma la propuesta metodológica de Carlos Quiroga quien, para diagnosticar la compatibilidad formal y simbólica de los objetos con la capacidad cognitiva e interpretativa por parte de los usuarios, desarrolla los conceptos de Affordances y «modelos conceptuales» aplicándolos en la evaluación de objetos con el fin de determinar los aciertos o desaciertos composicionales.

Palabras Clave: cognición, diseño, semiótica.

\section{Abstract:}

This work seeks to analyse the implications of neurocognitive sciences in design. Recent studies have allowed the reconceptualization of design from a semiotic approach. Scientists John O'Keefe, Edvard Moser, and May-Britt Moser have discovered the existence of cells in the brain whose system allows people to orient themselves, creating a mental map of physical space. Hence, the concept of Wayfinding is introduced, which is referred to as a way in which people can mentally plan to navigate from place to place or use objects, not as a simile of a visual-mental map, but as a process that it involves symbolic components and determining past experiences. Wayfinding demands different types of memory: episodic and usual (rigid) memories, their response from design is called Wayshowing, that is, the application of this knowledge to design. In this regard, the methodological proposal of Carlos Quiroga is taken, who, to make a diagnosis of the formal and symbolic compatibility of objects with the cognitive and interpretive capacity of the users, develops the concepts of Affordances and Conceptual Models applying them in the evaluation of objects in order to determine the compositional successes or failures.

KEYWORDS: cognition, design, semiotics.

\section{INTRODUCCIÓN}

El diseño ha transitado por un proceso histórico que le llevó a privilegiar aspectos estéticos y funcionales sin considerar aspectos centrales de la comunicación, entre ellos, la semiótica, así como fundamentos neurocognitivos. Esto trajo como consecuencia la aparición de productos incomprensibles o difíciles de accionar debido a interfaces complicadas y confusas. Las causas de su difícil comprensión o maniobra pueden ser variadas -alejamiento de modelos conceptuales, ausencia de Affordances, ambigüedad en la manera de accionar, etcétera- pero todas ellas estrechamente ligadas con procesos comunicativos, semióticos y cognitivos. 
Esta investigación responde al planteamiento acerca de las implicaciones de los procesos cognitivos en el procesamiento de comunicación generado por los diseñadores, para vincular el objeto de diseño con su usuario y facilitar tanto el uso como un adecuado desempeño a través de un «diseño intuitivo». Se responde con ello a la pregunta de investigación: ¿Cómo pueden contribuir los avances en las ciencias neurocognitivas en la mejora del proceso comunicativo detonado por el diseñador a través de su objeto de diseño?

Los últimos años han sido testigos de importantes avances en las ciencias neurocognitivas, los cuales han estado sustentados en investigaciones realizadas en torno al hipocampo y al cuerpo estriado, ambos componentes cerebrales estrechamente ligados a la comunicación y comprensión del entorno, por ello resulta importante su incorporación en el campo del diseño. El beneficio se traduciría en la toma de conciencia de los diseñadores por generar objetos que permitan una compresión intuitiva de su uso, función y manipulación sin producir frustración en el usuario. Se parte de la hipótesis de que si se incorporan los últimos avances de las ciencias neurocognitivas, el diseñador podrá incluir dichos conocimientos con la intención de mejorar la legibilidad de los productos de diseño a través de interfaces claras e intuitivas.

Se retoma la metodología de análisis desarrollada por el Mtro. Carlos Quiroga (2016), que se enfoca en los conceptos de «complejidad»y «complicabilidad». Se recurre al concepto de complejidad para generar cuatro categorías de análisis centrándose en la función del objeto y al concepto de complicabilidad para definir otras cuatro categorías de análisis centradas en el uso. Desde la perspectiva de este autor, se separan la función y el uso, debido a que la función responde a una interpretación racional propuesta por el emisor (diseñador), mientras que el uso se entiende como una interpretación subjetiva del objeto que hace el destinatario (usuario). Se toma de esta metodología dos variables que dan cuenta del enfoque cognitivo en la comunicación objeto-usuario: los Affordances y los modelos conceptuales, ambas variables serán analizadas en un objeto de diseño para evaluar su pertinencia.

Los Affordances se traducen como invitaciones de uso y se evidencian en las características morfológicas de los objetos que instan a ser utilizados de una manera en particular y no de otra. Los «modelos conceptuales», por su parte, son la creencia subyacente de una persona acerca de cómo funciona algo y de cómo los diseñadores representan ese uso por medio de una interfaz. Los objetos siguen modelos mentales de quienes conocen previamente su funcionamiento por dos razones: a) el objeto se parece a otros objetos y b) el objeto se asemeja a otros objetos que cumplen funciones similares (Quiroga, 2016). Los conceptos anteriores parten de una visión de la semiótica con un enfoque cognitivo, donde el Wayfinding y el Wayshowing se aplican con la finalidad de centrar la atención del diseñador en disponer sus planteamientos hacia un «diseño intuitivo» que no demande de su usuario preparación o conocimiento previo, sino que el uso del objeto procure ser de una manera intuitiva por asociación o por analogía.

Los resultados y hallazgos de este trabajo se apoyan en propuestas teóricas que parten de los avances de las ciencias cognitivas: el Wayfinding. Wayshowing, así como la consideración de la metodología de «complejidad»y «complicabilidad» en el diseño, avances que aplicados en el diseño intuitivo posibilitan una mirada analítica de los sistemas de comunicación contenidos en el objeto a través de la interfaz. Las conclusiones arrojan la importancia de estos conceptos para lograr una comunicación clara que permita definir, con base a aspectos neurocognitivos, las interfaces del objeto de diseño y hacerlo más intuitivo.

\section{MARCo TeÓRICo}

\section{1. El enfoque cognitivo en el diseño}

Los avances en las ciencias neurocognitivas permiten delinear nuevos enfoques en el diseño, ya que de manera intuitiva los diseñadores se han ido acercando a los código que, por herencia o construcción, posibilitan la comunicación con el usuario. Acorde con John O'Keefe (Hartley, Lever, Burgess y O'Keefe, 2014) el 
hipocampo constituye un componente cerebral ligado con un sistema de posicionamiento, distinguiendo lo que se denomina neuronas de lugar, atisbando en un proceso cognitivo que permite formar un mapa de ubicación que define nuestro actuar en el espacio y con los objetos (Aguilar, 2015).

A estas ideas se suman las de May-Britt y Evard Moser (Moser, Rowland y Moser, 2015) quienes se percataron que este posicionamiento cognitivo se apoya en coordenadas que precisan la navegación, identificando las neuronas denominadas células de cuadrícula (Aguilar, 2015). De esta forma se infiere una función mental hasta ese momento desconocida: la capacidad de orientación a través de la localización de puntos de interés, similar a un sistema de posicionamiento global mental que, convertidos en hábitos, facilitan el desplazamiento en un espacio o la manipulación de un objeto. Los sistemas de posicionamiento son generados en el hipocampo, mientras que los hábitos se generan en el cuerpo estriado del cerebro (Golfarb, Chun y Phelps, 2016). Se desprende de esto que los recuerdos están ligados a la información, por lo que se recupera el mapa mental del lugar donde se crea ese recuerdo. La memoria es el archivo de la identidad personal que se vincula al espacio y, en este sentido, también al diseño tanto de objetos como arquitectónico. De la misma manera, recientes estudios de las geociencias han contribuido a este discurso, introduciendo así, el concepto de imágenes mentales, las cuales se construyen tanto en el córtex cerebral como en algunos núcleos subcorticales: el cerebro humano actúa como un cartógrafo productor de imágenes mentales del entorno externo y representaciones entendidas como "trayectorias cognitivas internas" (Dell'Aversana, 2015).

Lo anterior refuerza las teorías de neuroplasticidad cerebral, así como sus enfoques localizacionistas y conexionistas (Garcés y Suárez, 2014), dado que las imágenes mentales son construcciones entendidas como un resultado de la interpretación del contexto, la cuales quedan almacenadas en la memoria y constituyen fundamentos asociativos para comprender el mundo, sus objetos y sus modos de operar. Esta teoría de neuroplasticidad establece que pueden existir variaciones celulares modificadas por el contexto y que una nueva distribución cortical puede tener lugar (Garcés y Suárez, 2014). Esto permite comprender el poder adaptativo del cerebro y la posibilidad de modificar modelos mentales si estos logran una mayor significación, al tiempo que rompe con la antigua teoría cuyo sustento se basaba en que los modelos mentales se construían en una edad temprana y quedaban fijos para el resto de la vida.

Hoy día, debido a los estudios del procesamiento cerebral de información y a un conocimiento más cercano de las funciones neuronales, se puede entender que, si bien los códigos tienen un fuerte sustrato cultural, existen bases biológicas estructuradas en el cerebro que le permiten al hombre una ubicación espacial ligada a experiencias y recuerdos que le configuran un mapa con el cual define la manera de interactuar con el objeto. El enfoque cognitivo en el diseño permite analizar conceptos como el Wayfinding y el Wayshowing, los cuales se desprenden de los avances en el conocimiento de la estructura y las funciones cerebrales para, posteriormente, aterrizarlas en modelos de análisis de los objetos y sus interfaces, lo que posibilita un manejo y uso adecuado de estos. La conexión entre el enfoque cognitivo y el diseño intuitivo subyace en la teoría constructivista, dado que de ella emergen teorías de interpretación y simbolización que facilitan una manera de entender cómo es que el sujeto o usuario establece una interfaz con el objeto de diseño. Acorde a las ideas de Arnheim (2001), esta interfaz no se limita a un primer contacto mediante los sentidos, sino que se construye a través de la experiencia que se genera con la interacción sujeto-objeto.

Para Rudolph Arnheim (2001), el pensamiento es un proceso inicialmente sensorial dado que se inicia con la percepción para, posteriormente, enriquecerse con aspectos culturales que se definen a través de valores axiológicos. De esta manera, el sustrato de todo aprendizaje es el contacto que se tiene con el mundo exterior y desde ahí se inicia la construcción de los conceptos. Este supuesto lo aleja de la escuela alemana del apriorismo cognoscente y lo acerca a la gestalt, de raíz eminentemente fenomenológica (Solano, 2013). Conforme a la escuela psicológica de la gestalt, la mente construye los conceptos partiendo tanto de la percepción como de la cultura, mientras que los sentidos se constituyen en puentes de pensamiento posibilitando la comprensión de la realidad externa, los aspectos culturales y biológicos, los cuales, a su vez, fundamentan la imaginación 
espacial. De esta manera, la construcción de conceptos estará definida por la suma de aspectos biológicos y el nivel de desarrollo cultural.

Las connotaciones mentales asociadas a las características de los objetos tales como color, textura, tamaño, forma, de la misma manera que las sensaciones de lejano, frío, acogedor, confortable son una extensión simbólica resultado de una construcción mental que se conforma de las diversas fuentes que nutren al cerebro y que no son de manera exclusiva empíricas, lo que determina aspectos definitivos en la generación, uso e interpretación de un objeto de diseño. La compleja relación que establece el usuario con el objeto y su entorno ha sido objeto de estudio de varios autores (Acha, 2008; Arnheim, 2001; García, 2000; Watzlawick, 2003). Estos autores abogan por un conjunto de sistemas que se entrelazan y tienen implicaciones desde el terreno de lo cognitivo hasta lo social, por ejemplo, la psicogénesis y la sociogénesis (García, 2000), de igual manera, ellos conjugan en estos sistemas una perspectiva individual y colectiva.

Amén de esta perspectiva, es desarrollado por Maturana (1996) un enfoque biológico respecto a la construcción mental de los conceptos, él aboga por una noción donde los sistemas son considerados sistemas autopoiéticos. De acuerdo con el autor, estos sistemas son definidos como un conjunto de procesos de producción de componentes recursivos que se manifiestan como una sola unidad. Su construcción perceptual funciona como un proceso interno e individual, relativo a cierto contexto, pero simultáneamente subjetivo y complejo. La importancia de estas ideas en el diseño estriba en entender que la percepción del objeto (y su uso) no está limitada a su representación o imagen, sino a toda la serie de relaciones que el objeto y el concepto de dicho objeto generan, ya sea por experiencias previas o por construcciones culturales, por lo tanto, resulta importante una concepción fenomenológica del objeto teniendo en cuenta todas las relaciones implícitas en ello.

Por su parte, Paúl Watzlawick (2003) propone un nuevo enfoque centrado en la comunicación teniendo como sustento la teoría de la «cognición situada» de Vigotsky. Bajo esta propuesta existen múltiples factores determinantes en la construcción mental que van desde una subjetivación de la realidad hasta una intervención activa en donde la mente construye una percepción para ir completando, a falta de información total o completa, una idea o un concepto. Esta afirmación, imposibilita la idea de la existencia de una realidad absoluta, unívoca y universal. Para Watzlawick (2003) los procesos comunicativos se constituyen en una manera de comprender cómo es que las personas construyen su realidad. Los principios que establece dicho autor, en términos de comunicación, son transferidos al diseño por Solano (2013), por consiguiente, es posible afirmar que:

a) Todo objeto de diseño será interpretado particularmente por el usuario, ya que los objetos pueden generar un concepto intelectual simultáneo a uno estético o emocional.

b) Todo objeto de diseño tiene, además de su significado convencional, un significado connotado.

c) El autor expresa su mensaje mediante el objeto de diseño, pero al ser descifrado por el usuario está sujeto a una amplia variación de interpretaciones que pueden ser tanto subjetivas como relativas.

d) El diseño comunica tanto a través de las formas visuales como de las connotaciones de la misma.

e) En los objetos de diseño existen dos tipos de modelos: los construidos por una hegemonía (modelos conceptuales) y los construidos en un contexto local, ambos en iguales condiciones, lo que coloca en tela de juicio los roles de autoridad que han querido ejercer, en términos de comunicación, los diseñadores.

Watzlawick (2003) distingue dos tipos de realidades:

a) Aquellas que se construyen con el fundamento de la percepción y que tienen la cualidad de ser verificables, las cuales denomina de primer orden.

b) Aquellas que aluden a una construcción más compleja y que refieren a la significación o al valor simbólico que se le otorga, de manera subjetiva, a un objeto o un mensaje, las cuales denomina de segundo orden.

Como se aprecia, existe un paralelismo entras las ideas de Watzlawick respecto a los tipos de realidad con la teoría de Saussure acerca del signo bifacial que refieren a la denotación y a la connotación. De la misma manera Acha (2008) propone un análisis subjetivista-relativista que distingue como «proceso ontogenético 
de la percepción», bajo este término afirma que la percepción no es unívoca, ya que presenta diferencias no solo de carácter biológico sino psicológico, debido a la influencia que ejerce en nosotros el entorno, el cual nos impone configuraciones (denominadas gestalten) social y culturalmente determinadas. En concordancia con la teoría de la gestalt, se establece que la realidad absoluta no existe dado que cada persona construye su propia imagen mental, esta imagen es el resultado de los pensamientos y sentimientos que los estímulos provocan. Este modelo de proceso cognitivo se asimila al desarrollado por el Dr. George Miller, se trata del «modelo de chuking» en el que el cerebro, ante fenómenos complejos, reduce la información en trozos o semas para facilitar su interpretación y después los integra con el tamiz de su experiencia y entorno.

También en la teoría analógica de Beuchot (2008) es posible identificar un componente social en las ideas de las personas que coinciden en un mismo tiempo y espacio (entendido como imaginario social), dicho componente social predomina sobre lo personal. Las similitudes o puntos en común que participan en la construcción de conceptos se entienden como analogías (Beuchot, 2012). La analogía participa en la interpretación como un elemento unificador de fuerte carácter social. La analogía "no da lo que significa de manera idéntica, pero lo da de manera suficiente" (Beuchot, 2008, p. 141).

En el mismo orden de ideas, Umberto Eco (2017), en su intentio operis, desplaza la importancia del emisor al receptor en el sentido de que este genera múltiples interpretaciones delimitando la diversidad de conexiones que la analogía le permite, reconociendo una analogía dominante de carácter social que puede distinguir de las analogías secundarias de carácter individual. En el campo del diseño, la analogía principal establece una relación hegemónica de carácter social producto de un consenso que trasciende, en consecuencia, a un lenguaje cercano y comprensible.

\subsection{Wayfinding, Wayshowing y el «diseño intuitivo»}

Se entiende por diseño intuitivo aquel que ofrece una mirada sobre la posibilidad que tiene una persona de interactuar con los objetos que le rodean sin que ello implique una carga o esfuerzo cognitivo consciente ( Brandes, Stich y Wender, 2009). Para lo anterior es necesario que el diseñador se centre en los comportamientos habituales, en la experiencia y en los modelos mentales preexistentes de su usuario, más que centrarse en aspectos creativos o novedosos del objeto de diseño. El diseño intuitivo facilita el uso y la comprensión de un objeto para ponerlo en funcionamiento mediante soluciones obvias sin que existan confusiones o complicaciones que impliquen una carga consciente para tomar decisiones en las diferentes etapas del proceso.

Si bien no existen propuestas teóricas que definan cabalmente al diseño intuitivo y regularmente se liga este concepto al diseño web, el diseño intuitivo emerge de planteamientos de autores como Chaves (2020) y Papanek (1995) quienes valoran lo intuitivo como un aspecto deseable en todo objeto de diseño por el hecho de tener su origen en la experiencia y en el conocimiento pasado del usuario. Norberto Chaves (2020) relaciona lo intuitivo con el pensamiento inconsciente. Para este autor, el inconsciente complementa a la consciencia y la razón (por tanto, entonces, incompletas) dado que en este tipo de pensamiento se encuentra almacenada la información acumulada, constituyendo así el insight del usuario: situaciones, conocimientos y experiencias vividas. Por su parte, Papanek (1995) reconoce, en su libro The Green Imperative: Ecology and Ethics in Design and Architecture, a los inuits como los mejores diseñadores, reconociendo su alejamiento del diseño racional por un diseño que soluciona empíricamente sus problemas de una manera experimental e intuitiva.

En otro orden de ideas, el Wayfinding se entiende como el conjunto de sistemas de información que brindan una guía a las personas para desplazarse en ambientes físicos o comprender mejor los espacios y los objetos de diseño. Al entenderse como un constructo mental su enfoque se centra en la diversidad existente en la capacidad de las personas, así como en la variabilidad generada por cuestiones físicas, sociales o culturales relacionadas con el ambiente en el que se desarrollan. Existen elementos comunicativos que los diseñadores 
han manejado y que culturalmente son reconocidos; bajo el enfoque del Wayfinding estos conceptos se traducen en principios que debieran ser vigilados de manera cercana para que, en conjunción con el diseño universal, se mejore la comunicación para todos los usuarios. Los principios del Wayfinding, según Mark A. Foltz (1998) son:

"1) Crear una señal o imagen de un objeto determinado que permita discriminarlo de todos los demás objetos. 2) Utilizar puntos de referencia que permitan construir señales de orientación. 3) Crear rutas bien estructuradas para su uso. 4) Identificar por regiones, generando subdivisiones en los componentes con un carácter visual diferenciado. 5) No proporcionar a los usuarios un amplio abanico de opciones de navegación o uso, para evitar confusiones. 6) Proporcionar mapas de uso. 7) Brindar señales evidentes en los puntos donde se deberá tomar la decisión. 8) Permitir una visión en prospectiva, esto es, evitar sorpresas y claramente mostrar lo que suceda a continuación" (p. 60).

Partiendo de la premisa que el Wayshowing posibilita el Wayfinding, Per Molleru (2013), diseñador y académico danés, reconfigura el papel pasivo del Wayfinding (el qué) a partir de su capacidad cognitiva que intuitivamente permite la ubicación y orientación para dirigir la mirada a las implementaciones que coadyuven al desarrollo de esta capacidad cognitiva: el Wayshowing (el cómo). Es decir, una vez comprendida la capacidad de los seres humanos de orientarse a través de códigos neurocognitivos de gran simpleza, la idea es perpetuar de manera consciente dichos códigos en el diseño. El concepto del Wayshowing es un término acuñado por Mollerup quien desde esta trinchera aboga por la simplicidad como base del diseño. Para él, la manera pertinente de mostrar el camino es generar una serie de códigos, ya inmersos en el cerebro humano, para después sistematizarlos como un lenguaje que oriente al usuario en el espacio independientemente de sus condiciones y, con ello, contribuir con los espacios inclusivos.

Para Mollerup la base de este nuevo código recae en dos principios básicos del diseño: simplicidad y redundancia. La simplicidad parte de una propuesta funcional donde el diseñador se apoye en los procedimientos perceptivos, cognitivos y de interacción según los cuales sean eliminados elementos que compliquen los desplazamientos o configuraciones del lugar, esto por considerarlos, en su composición, elementos que generen ruido, errores o malos entendidos. La redundancia, por su parte, constituye el eje de la sistematización de códigos y en ello se sustenta la legibilidad del objeto de diseño.

\subsection{Affordances y modelos conceptuales como conceptos cognitivos para el «diseño intuitivo»}

La metodología plantea los conceptos de «complejidad» y «complicabilidad», a la vez pretende comprender los procesos comunicativos que se generan entre los objetos de diseño y los usuarios. En este sentido, complejidad se concibe como el conjunto de las características y los componentes descriptibles entendiendo al objeto a partir de un sistema compuesto por interrelaciones de partes, características formales, funciones, etc. La complejidad posibilita la identificación del objeto por su aspecto sin, necesariamente, utilizar ese objeto. Por su parte, se entenderá la complicabilidad como la dificultad para intuir el uso o las funciones de algún objeto cuya responsabilidad recae en el objeto y no en el usuario.

La metodología propone cuatro categorías de análisis para cada concepto, en el caso de complejidad son: primero, modelos conceptuales; segundo, estructura modular y semas; tercero, señales y cuarto, potencialidades. Por su parte, para complicabilidad son, primero, ergonomía; segundo, Affordances; tercero, protocolo y secuencia de uso, y cuarto, tiempo de aprendizaje. Sin embargo, en este trabajo se retoman las dos categorías directamente relacionadas con los fundamentos neurocognitivos. Estas dos categorías se denominan Affordances y modelos conceptuales.

Los Affordances hacen referencia a la percepción y las conductas aprendidas en relación con los objetos. Estos se traducen como invitaciones de uso e indican las características morfológicas de los objetos que invitan a que sean utilizados de una manera en particular, o bien, para llevar a cabo determinadas acciones en lugar de otras. El término fue desarrollado, por primera vez, por el psicólogo J.J. Gibson para explicar la manera en 
que las personas se relacionan con su entorno, esto con relación a la forma de los objetos o y sus elementos incorporados, dado que la forma define o acusa la función de los mismos (Gibson, 1979), es así que sabemos por dónde asir una taza o por dónde destapar un recipiente. Posteriormente, Donald Norman adopta este concepto para su aplicación en la teoría del diseño en su libro La psicología de los objetos cotidianos (2010). Se puede definir a los Affordances como los elementos percibidos de manera intuitiva que el objeto brinda al sujeto y que sugieren invitaciones de uso. En este trabajo se le da importancia a este concepto y se toma como categoría de análisis, puesto que el entendimiento de los Affordances ayuda a la interpretación operativa del objeto y supera la división entre lo subjetivo y lo objetivo, en tanto que su comprensión conceptual no pertenece exclusivamente a solo alguna de estas dos dimensiones, sino que surge de la relación entre ambas. Los Affordances son percibidos como significantes en el objeto e interpretados como significados por las personas; en otras palabras, equivale a un proceso de semiósis de percepción producida por el objeto.

El modelo conceptual, por su parte, se define como la creencia subyacente de una persona acerca de cómo funciona algo y de la manera cómo los diseñadores representan ese uso a través de una interfaz. Los objetos siguen modelos conceptuales de quienes conocen previamente su funcionamiento por dos razones: a) el objeto se parece a otros objetos análogos que cumplen la misma función primaria que la persona reconoce por su propia experiencia y b) el objeto se asemeja a otros objetos que cumplen funciones similares. Como muestra, unas tijeras se asemejan a una cizalla por su función y, al mismo tiempo, a unas pinzas por su modo de uso. La forma del objeto, siguiendo modelos conceptuales de otros objetos, le facilita al usuario saber qué es y para qué sirve. Estos modelos conceptuales residen en la mente de las personas como constructo de un diseño y se constituyen en aquello que el usuario cree sobre cómo funciona un sistema, de allí que en esa etapa también se entiendan como modelos mentales (Norman, 2011).

En nuestro ámbito del diseño, la diferencia entre un modelo conceptual (construido por el diseñador o por diseños previamente conocidos) y un modelo mental es, en estricto sentido, que este último es un tipo de representación de la realidad externa no necesariamente construido por un diseñador. Un modelo conceptual apropiado permite predecir el efecto de la acción que se va a realizar. El usuario tiene modelos mentales previos que le facilitarán la interacción con el objeto, al mismo tiempo que el diseñador de dicho objeto posee modelos conceptuales que se verán reflejados de manera formal en el objeto. La interacción con el objeto en cuestión se produce en el momento en que convergen los dos modelos diferentes, el del diseñador y el del usuario. El resultado ideal de un buen diseño se logra cuando el modelo conceptual del diseñador y el modelo mental del usuario son equivalentes (Deni, 2002). Es posible decir que cuando los modelos mentales del usuario coinciden con los modelos conceptuales del diseñador, son próximos o equivalentes, entonces el objeto es menos complejo.

\section{Metodología}

Esta metodología refiere a un carácter analítico que centra su atención en aspectos comunicativos de los objetos con las categorías ya señaladas. Consiste en una descripción detallada del objeto en cuanto a sus componentes y uso seguida del análisis de cada categoría. Para analizar los modelos conceptuales se siguió el siguiente método: se seleccionó una muestra de diez personas, la cual fue tomada de una población de usuarios potenciales de cafeteras para comprobar el peso de los modelos conceptuales en ellas. A cada persona se le presentó el objeto a analizar y, posteriormente, se le aplicó como instrumento una encuesta con dos preguntas base: 1) ¿qué es el objeto que se encuentra frente a ti?,2) ¿cómo crees que funciona el objeto? Una vez realizada la encuesta se analizan las respuestas identificando las siguientes categorías: por un lado, la relación formal con los objetos convencionales de su tipo y, por otro, la identificación de los componentes principales del objeto. Las respuestas fueron evaluadas numéricamente conforme mostraban facilidad de identificación (cercanía a modelos conceptuales), lo que permitió saber qué tanto el modelo presentado se alejaba o no de otros modelos conceptuales y, en consecuencia, pudiera resultar complejo el funcionamiento de este y mostrar un bajo nivel 
de diseño intuitivo. Los resultados evaluaron, en una escala del cero al diez, la facilidad de identificación en cada rubro, siendo diez el nivel máximo de dificultad y cero la facilidad máxima.

Por su parte, para analizar los Affordances se partió de un estudio etnográfico en torno al objeto, lo que supuso tomar una muestra de treinta personas y hacer observaciones para indagar las reacciones de acuerdo a las interacciones comunicativas entre los usuarios y el objeto. En este estudio, el método fue el siguiente: se les colocó a los usuarios el objeto en frente y se les pidió a estos que lo operaran. No se les instruyó nada más, ni se les especificaron los componentes de los objetos. Después, fueron evaluados con base a un instrumento escrito para registrar las experiencias que resultaban evidentes: dificultad para realizar la labor, secuencia de uso y tiempo de realización de la labor, tanto cuantitativa como cualitativamente (se registraban incidencias). Este instrumento evaluaba en una escala del cero al diez la dificultad en cada rubro, siendo diez el nivel máximo de dificultad y cero la dificultad mínima.

\section{Resultados: anÁlisis de Affordances y modelos conceptuales en el obJeto de DISEÑO}

Para este apartado se toma como referencia el trabajo desarrollado por alumnos de Diseño Industrial del Instituto Tecnológico y de Estudios Superiores de Monterrey (ITESM), Campus Toluca y Ciudad de México, entre agosto del 2018 a diciembre del 2019. El trabajo consistió en analizar y evaluar un objeto de uso cotidiano con base en las categorías semióticas de la metodología de complejidad y complicabilidad, el enfoque del Wayfinding y Wayshowing y el diseño intuitivo. A continuación, se presentan dos casos de análisis.

\section{1. Cafetera taurus cm-100 élite por Sara María López Montalbán}

\subsubsection{Descripción del objeto de diseño}

La cafetera taurus cm-100 élite está hecha de acero inoxidable y plástico. Sus características principales son la rapidez y portabilidad de la máquina. Está diseñada para un uso individual, por lo que el tamaño y sus funcionalidades son limitadas. Sus características y componentes son los siguientes. Véase la Figura 1. 

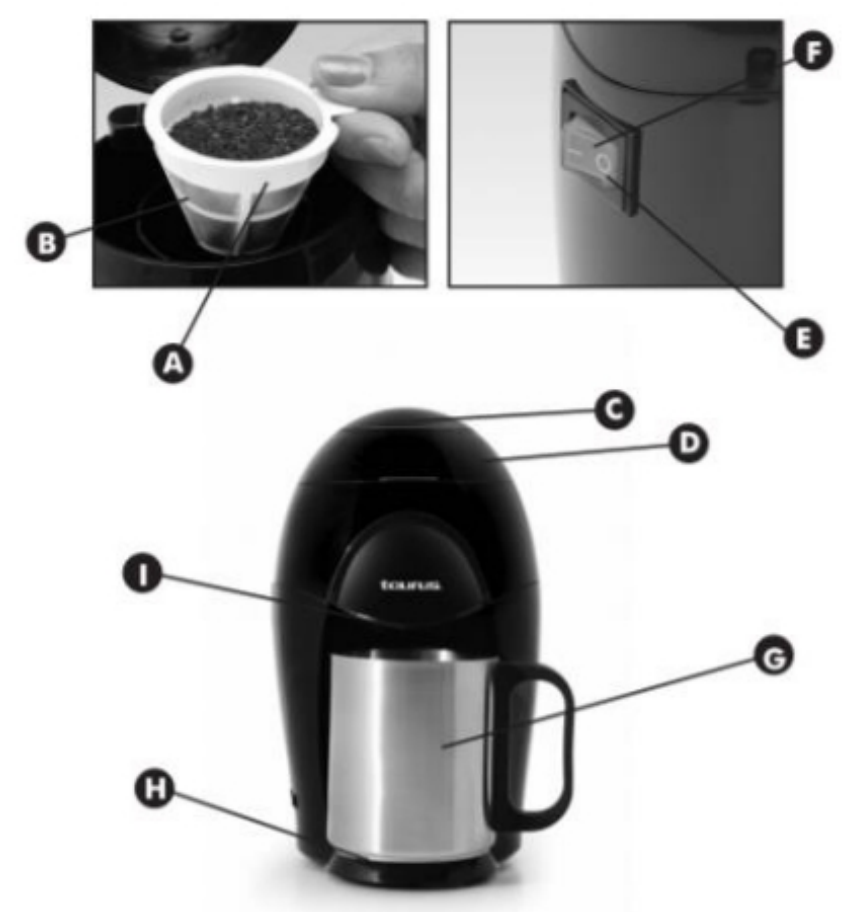

Identificación de las partes
A Filtro extraible
B Porta filtro
C Tapo del depósito
D Depósito de agua
E Interruptor de puesta en marche
F Piloto luminoso
G Tozo de ocero inoxidabl
H Bondejo recoge gotos
I Dispositivo de goteo

Figura 1.

Muestra de cafetera taurus cm-100 élite analizada en este estudio, López Montalbán, 2017.

\subsubsection{Análisis de modelos conceptuales y Affordances}

\subsubsection{Modelos conceptuales}

Luego del análisis de las respuestas se concluye que la composición formal de la cafetera taurus cm-100 élite es distinta a la composición formal de las cafeteras convencionales, es decir, aquellas cafeteras de goteo para más de seis tazas que incluyen una jarra de cristal con indicador de la capacidad de las tazas. Véase la Figura 2. 


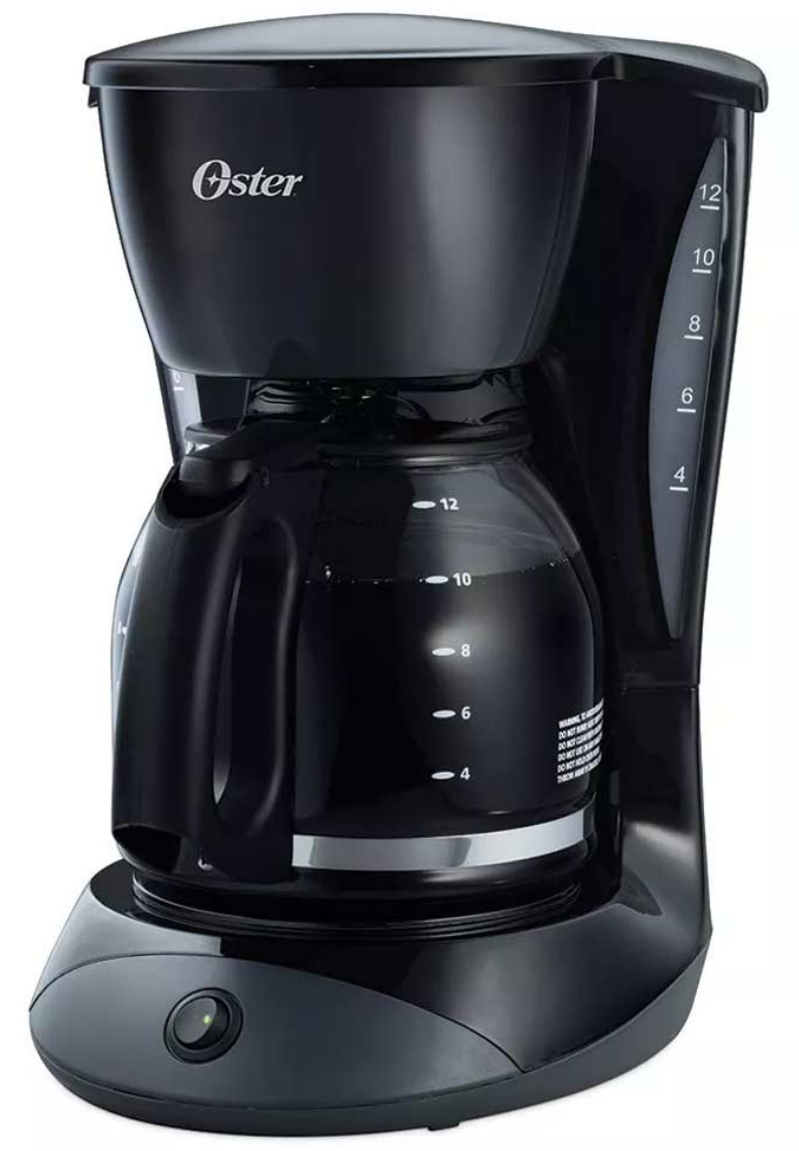

Figura 2.

Imagen de cafetera convencional de jarra de cristal, modelo 2017.

En la cafetera analizada la función principal no se identifica a simple vista, ya que el filtro y el depósito de agua están ocultos en el cuerpo del objeto. Sin embargo, una vez abierta la cubierta, esta se vuelve evidente, ya que por dentro sí se asemeja de forma completa a las cafeteras comerciales. Además, la taza que viene como complemento hace que sea más fácil identificar el funcionamiento de la cafetera, puesto que esta se parece a las tazas que circulan en el mercado, al igual que la marca escrita en el cuerpo de ella, la cual se relaciona con objetos de funciones similares. Por este motivo, se deduce que la complejidad de la cafetera taurus $\mathrm{cm}-100$ élite es baja, ya que los modelos conceptuales son entendibles en su mayoría, aunque sí se necesita una exploración táctil e interactiva (abrir la tapa del depósito) para confirmar la suposición inicial de que es una cafetera.

\subsubsection{Affordances}

De los resultados de la investigación etnográfica, se rescata lo siguiente:

- Al abrir la tapa del depósito, no todos utilizaron la pestaña. Dos de las personas la abrieron solo por la fricción/adhesión de sus dedos con la superficie de esta.

- Lo que más dificultad presentó fue mover el ducto de agua. Una persona lo zafó ya que lo jaló hacia arriba. Los otros dos sí lo giraron, pero cada uno en un sentido distinto.

- Retirar el filtro portátil fue fácil y colocarlo también, ya que no lo cambiaron de posición al sacarlo y ponerle el café, por lo que la posición permaneció igual y no tuvieron que experimentar con la silueta del borde.

- Colocar el agua y cerrar la tapa no representó ninguna dificultad. Todos lo hicieron de la misma manera. 
- Para accionar el interruptor dos personas lo hicieron sin siquiera verlo, solo lo oprimieron y reconocieron que había encendido porque empezó a sonar la cafetera. La otra persona volteó el cuerpo de esta y accionó el botón. Regresó el cuerpo a su posición original cuando vio que prendió el foco y que empezó a funcionar.

Por lo anterior, se concluye que los elementos de la cafetera taurus cm-100 élite se refuerzan dentro de los códigos culturales de las personas que están en contacto con ella. Ninguna acción representa complejidad significativa dentro de esta categoría.

\subsection{Firephant extintor de fuego portátil por Daniel Cuevas Novia}

\subsubsection{Descripción del objeto de diseño}

Herramienta portátil de fácil y rápido manejo para apagar o contener el fuego en un área, puede ser desplazada por una sola persona para sofocar el fuego través de un mecanismo de propulsión que libera un agente extintor en forma de polvo. Su diseño curvo le otorga un aspecto elegante y puede colocarse como elemento de decoración interior. La mayoría de los extintores tienen un aspecto técnico y normalmente se colocan fuera de la vista (esquinas, dentro de cabinas de vidrio, debajo del escritorio). Este extintor puede ser colocado como elemento decorativo para un rápido y crítico momento de uso en caso de emergencia. Véase Figura 3.

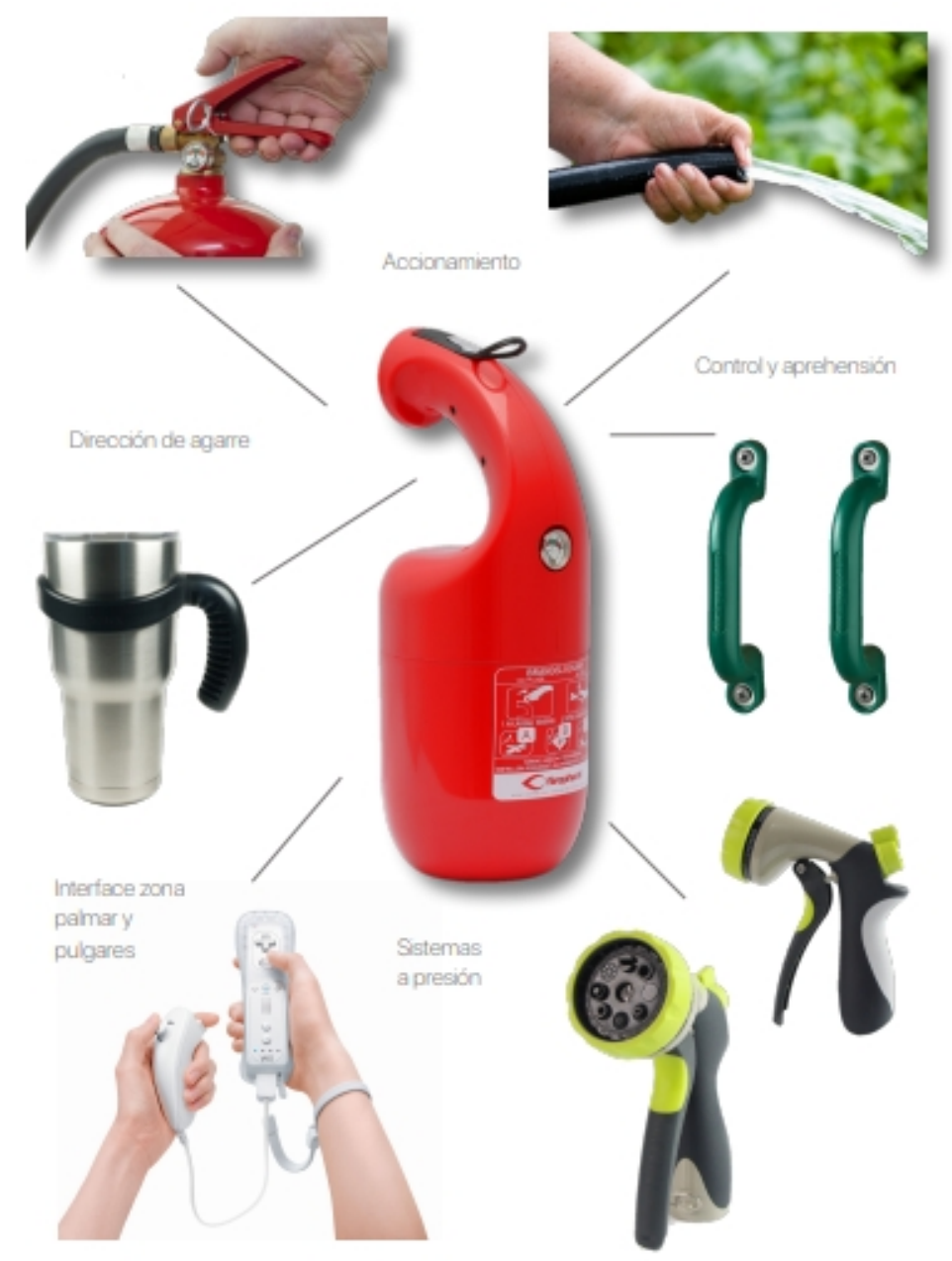

Figura 3.

Muestra de Firephant extintor de fuego portátil, Cuevas Novia, 2018. 


\subsubsection{Análisis de modelos conceptuales y Affordances}

\subsubsection{Modelos conceptuales}

Los resultados en este caso fueron los siguientes: este extintor resulta una herramienta crítica para usarse en caso de incendio, su forma comunica el modo de uso rápidamente, atiende a un modelo conceptual casi completo ya que el color y la forma cilíndrica corresponden a un extintor como herramienta universal. Además del modelo conceptual más evidente establecido por el color rojo que se relaciona con advertencia o con la frase de "usarse en caso de emergencia", la forma curvada de la manija también le indica al usuario que es un componente de agarre o sujeción palmar por la morfología semejante a otros diseños como las manijas de auto y la regadera para plantas. Véase Figura 4.

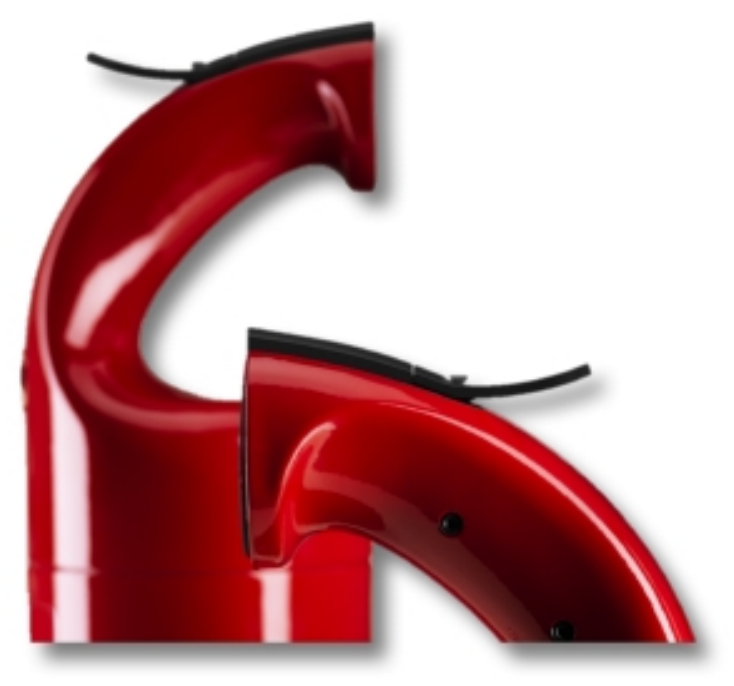

Figura 4 .

Modelos conceptuales que atienden a la forma de sujeción y empuñadura del extintor Firephant, Cuevas Novia, 2018

\subsubsection{Affordances}

El extintor comunica e invita de una forma intuitiva el uso de este, gracias a los modelos conceptuales anteriormente descritos, la forma de trompa de elefante indica, a través de una dirección, por donde tomarse. Además, el ensanchamiento del mango hasta la zona de apertura refuerza el sentido de uso y agarre. El componente de liberación o escape tiene una forma anillada que apunta hacia el usuario indicando que puede jalar hacia esa dirección con tan solo meter un dedo y tirar. El botón es un elemento que se encuentra a nivel pulgar y no a nivel palmar, ya que se busca un mayor control por parte del usuario. Se debe recordar que los extintores y muchos sistemas de presión están diseñados para usarse con la zona palmar y distal del usuario ocasionando una fatiga o molestia al estar sujetando y a la vez ejerciendo presión. Este diseño se caracteriza por una interface que permite ejercer la presión de apertura con un solo dedo.

\section{Hallazgos y CONCLUSiones}

El enfoque cognitivo en el diseño es una herramienta que, bajo la perspectiva de la comunicación y la semiótica, puede establecer condiciones claras en la interfaz de un producto. Los avances neurocognitivos muestran que el cerebro almacena información que se va construyendo con la experiencia, pero que también 
parte de un funcionamiento cerebral biológicamente heredado que brinda principios de ubicación, así como de lectura del espacio y de los objetos de manera natural. Partiendo de estas ideas, tanto el diseño intuitivo como el Wayfinding y Wayshowing buscan comprender y aprovechar como recursos estas condiciones cognitivas, construidas o heredadas, para lograr el vínculo que permita la comprensión del uso y función de un objeto de diseño.

En la propuesta metodológica que observa la complejidad y la complicabilidad de un objeto de diseño, se analizan aspectos relacionados con la naturaleza cognitiva del usuario: los Affordances y los modelos conceptuales, mediante los cuales el diseñador ha de aprovechar los referentes de su usuario para lograr interfaces intuitivas que no demanden al usuario tiempos de aprendizaje para comprender el protocolo de uso de un objeto, a pesar de sus innovaciones. Entre los hallazgos encontrados en el presente trabajo de investigación, se destacan la cercanía de las diversas posturas teóricas analizadas que, viniendo de diferentes esferas, coinciden en principios que muestran su preocupación por rescatar aspectos ya codificados previamente para lograr interfaces intuitivas. Estos principios teóricos, después comprobados en la investigación de campo se concentran en la Tabla 1.

Tabla comparativa

\begin{tabular}{|l|l|l|}
\hline \multicolumn{3}{|c|}{ Principios cognitivos en el diseño intuitivo } \\
\hline Diseño intuitivo & Wayfindind y Wayshowing & Complejidad y complicabilidad \\
\hline $\begin{array}{l}\text { Centrado en } \\
\text { comportamientos habituales, } \\
\text { en la experiencia y en los } \\
\text { modelos conceptuales } \\
\text { preexistentes. }\end{array}$ & $\begin{array}{l}\text { Crear señales y puntos de } \\
\text { referencia para ser } \\
\text { reconocidos por el usuario. }\end{array}$ & $\begin{array}{l}\text { Modelos conceptuales definidos } \\
\text { como la creencia subyacente de } \\
\text { una persona acerca de cómo } \\
\text { funciona algo. Ello se apoya en } \\
\text { un conocimiento o experiencia } \\
\text { previa. }\end{array}$ \\
\hline $\begin{array}{l}\text { El diseño facilita el uso y la } \\
\text { comprensión de un objeto } \\
\text { para ponerlo en } \\
\text { funcionamiento mediante } \\
\text { soluciones obvias. }\end{array}$ & $\begin{array}{l}\text { Generar un carácter } \\
\text { visual/composicional } \\
\text { diferenciados. }\end{array}$ & $\begin{array}{l}\text { Affordances como indicaciones } \\
\text { de las características } \\
\text { morfológicas de los objetos que } \\
\text { invitan a utilizarlas de una } \\
\text { manera en particular. }\end{array}$ \\
\hline $\begin{array}{l}\text { Evitar confusiones o } \\
\text { complicaciones que } \\
\text { impliquen una carga } \\
\text { consciente para decidir en } \\
\text { las diferentes etapas del } \\
\text { proceso. }\end{array}$ & $\begin{array}{l}\text { No proporcionar un abanico } \\
\text { amplio de toma de } \\
\text { decisiones. }\end{array}$ & $\begin{array}{l}\text { Affordances como los elemes } \\
\text { percibidos de manera intuitiva } \\
\text { que sugiere invitaciones de uso } \\
\text { de una determinada manera. }\end{array}$ \\
\hline
\end{tabular}

Tabla 1. Tabla comparativa entre los diferentes principios cognitivos en el diseño intuitivo, Solano, 2020.

La tabla comparativa establece aspectos que resultan coincidentes entre los principios del diseño intuitivo, el Wayfinding y el Wayshowing, así como de la propuesta desde los conceptos de la complejidad y la complicabilidad. Existen tres puntos claramente perceptibles entre las tres propuestas:

a. Puntos de reconocimiento o de referencia generados a través de la experiencia con base a modelos conceptuales.

b. La relación existente entre la configuración o composición morfológica con el uso intuitivo del objeto.

c. Claridad en los Affordances que eviten ambigüedades a través de múltiples opciones que pueden resultar confusas. 
Como se aprecia, existen nexos perceptibles desde la semiótica en los diferentes discursos del diseño centrados en lo cognitivo, la comunicación y las interfaces entre el objeto de diseño y el usuario. En ello estriba la importancia que arroja el conocimiento de los fundamentos neurocognitivos como una base o un sustrato que consolide los planteamientos del diseño hacia un diseño intuitivo. Otro hallazgo interesante es el referente a la teoría de neuroplasticidad cerebral, con lo que se abre al diseño la posibilidad de modificar modelos mentales, si estos logran un cambio gradual de mayor significación sin producir un choque que derive en confusión y frustración.

Esto queda comprobado en los análisis y evaluaciones de los objetos de diseño desarrollados por los alumnos del Tecnológico de Monterrey, donde resulta evidente la relación analógica que el usuario hace al momento de interactuar con un objeto de diseño: si este le da pautas de uso a través de la morfología (como la forma de asa), o por medio de la cercanía con prototipos (taza de la cafetera), o si le concede significados como el rojo del extintor (que se asocia al fuego y al peligro), si ocurre algo de lo descrito anteriormente el nivel de comprensión con el objeto se potencializa, mientras que, en el caso contrario, la posible frustración del usuario llevará al fracaso de un diseño propuesto. Se concluye que el código, el mensaje y la comunicación resultan básicos en el diseño, lo que obliga al diseñador a estudiar y a comprender la manera en que el usuario construye sus ideas y sus argumentos desde diversos fundamentos, tanto cognitivos como sociales y culturales.

Conocer e indagar sobre los avances neurocognitivos -las implicaciones del hipocampo en la conformación de un mapa de ubicación que define nuestro actuar con los objetos, los hábitos que se generan en el cuerpo estriado del cerebro, las imágenes mentales que se construyen en el córtex cerebral y en algunos núcleos subcorticales-, así como sus implicaciones en el diseño intuitivo, los avances y aportes del Wayfinding y el Wayshowing, junto a la metodología semiótica desde la complejidad y la complicabilidad posibilitan el replanteamiento, la revisión y una reformulación de la manera en que el diseñador propone sus proyectos. Pensar en el usuario desde un enfoque emotivo, estético o participativo no basta, es importante también la consideración de los aspectos cognitivos para asegurar que la comprensión del objeto, su función y uso por asociación genere interfaces naturales y lógicas que no demanden una carga cognitiva por su complicabilidad o sus múltiples (y confusas) opciones, para de esta manera, derivar en una valorización e impulso del diseño intuitivo que tiene otra posibilidad, quizás, aun más rica por explorar: el abordaje desde el diseño universal e inclusivo.

\section{ReFERENCiAS}

Acha, J. (2008). La apreciación artística y sus efectos. Ciudad de México: Trillas.

Aguilar, R. (2015). El sistema de posicionamiento cerebral: Premio Nobel en Fisiología y Medicina 2014. Revista de la Facultad de Medicina de la UNAM, 58(3), 53-58. Recuperado de https://www.medigraphic.com/pdfs/facm ed/un-2015/un153i.pdf

Arnheim, R. (2001). La forma visual de la Arquitectura. Barcelona: Gustavo Gilli.

Beuchot, M. (2008). Perfiles esenciales de la hermenéutica. México: Fondo de Cultura Económica.

Beuchot, M. (2012). Entrevista sobre hermenéutica analógica icónica (E. E. Meneses, entrevistador). En Crítica sistémica del fenómeno arquitectónico (tesis doctoral). Universidad Autónoma del Estado de México.

Brandes, U., Stich, S. y Wender, M. (2009). Design by Use: The Everyday Metamorphosis of Things. Basel: Birkhäuser Architecture.

Chaves, N. (10 de junio de 2020). La intuición en diseño. Archivo de Norberto Chaves. https://www.norbertochave s.com/articulos/texto/la_intuicion_en_diseno

Dell'Aversana, P. (2015). The Brain Behind the Scenes-Neurobiological Background of Exploration Geophysics. First break, 33(7), 41- 48.

Deni, M. (2002). Oggetti in azione. Semiotica degli oggetti: dalla teoria all'analisi. Milan, Italia: Franco Angeli.

Eco, U. (2017). Los límites de la interpretación. México: Debolsillo. 
Foltz, M. A. (1998). Designing Navigable Information Spaces. Saint Louis: Massachusetts Institute of Technology.

Garcés, M. y Suárez, J. (2014). Neuroplasticidad: aspectos bioquímicos y neurofisiológicos. CES Medicina, 28(1), 119-131. Recuperado de https://www.redalyc.org/pdf/2611/261132141010.pdf

García, R. (2000). El conocimiento en construcción. De las formulaciones de Jean Piaget a la teoría de los sistemas complejos. Barcelona: Gedisa.

Gibson, J. J. (1979). The Ecological Approach to Visual Perception. Boston: Houghton Mifflin.

Golfarb, E., Chun, M. y Phelps, E. (2016). Memory Guided Attention: Independent Contributions of the Hippocampus and Striatum. Neuron, 89(2), 317-324.

Hartley, T., Lever, C., Burgess, N. y O'Keefe, J. (2014). Space in the Brain: How the Hippocampal Formation Supports Spatial Cognition. Philos. Trans. Royal Society B, 369, 1-18. Recuperado de https://royalsocietypubli shing.org/doi/pdf/10.1098/rstb.2012.0510

Maturana, H. (1996). La realidad: ¿objetiva o construida? México: Anthropos.

Molleru, P. (2013). Wayshowing>Wayfinding: Basic and Interactive. Amsterdam: BIS Publisher.

Moser, M., Rowland, D. y Moser, E. (2015). Place Cells, Grid Cells, and Memory. Cold Spring Harbor Perspectives in Biology, 7(2), 1-16. Recuperado de https://cshperspectives.cshlp.org/content/7/2/a021808.full.pdf + html

Norman, D. (2010). La psicología de los objetos cotidianos. San Sebastian: Nerea.

Norman, D. (2011). Living with complexity. Cambridge: The MIT press.

Papanek, V. (1995). The Green Imperative: Ecology and Ethics in Design and Architecture. New York: Thames and Hudson.

Quiroga, C. (2016). Herramienta para el análisis de la complejidad y la complicabilidad en objetos de uso. Aplicación a tres cepillos de dientes. Ciudad de México: Universidad Autónoma Metropolitana, Unidad Xochimilco.

Solano, E. (2013). Crítica arquitectónica sistémica: un enfoque cognitivo, semiótico y simbólico del fenómeno de la supermodernidad en México. Toluca: UAEM.

Watzlawick, P. (2003).¿Es real la realidad? Confusión, desinformación, comunicación. Barcelona: Herder Editorial. 